TURIZAM

Volume 18 , Issue 4

166-174 (2014)

\title{
Mobile Technologies in Museum Exhibitions
}

\author{
Sandra Medić, Nataša Pavlović*
}

Received: July 2014 | Accepted: September 2014

\begin{abstract}
In order to be up-to-date and give visitors a memorable and unique experience, museums are including usage of digital technologies in their exhibitions. Even though museums in Serbia are very important part of tourism offer, they still have traditional settings that are poorly interpreted. The majority of them have a scientific and historical review which is unattractive for various target groups of visitors and for museums it's important to continually try out new ways in interpretation of their settings.

Because technology continues to rapidly change the way we communicate, cultural institutions should adapt to new ways of communication with their visitors.

This paper examines mobile technologies that can be used in museums to give visitors a different experience and transfer the knowledge innovatively. In that way it will be presented the modern concept of presentation of museum exhibitions, focusing on usage of mobile devices through mobile applications and $Q R$ codes. The paper provides the broad understanding of usage mobile technologies in museum exhibitions with its advantages and limitations. The research results can help the museums management to improve interpretation and communication with visitors and enrich the visitor experience.
\end{abstract}

Key words: museums, mobile technologies, interpretation, promotion, cultural tourism

\section{Introduction}

There is an increasing trend of interest in cultural tourist products in the world today, and the World Tourism Organization expects that the cultural tourism market would be among the five most important segments of the tourist market in the future (WTO, 2OOI). There is no doubt that cultural tourism becomes more and more important form of tourism.

Today's most popular tourist destinations are the ones which adjust their offer to tourist needs giving them a range of different activities and experiences. In that case, a cultural product would be a unique emotion, experience, since sightseeing itself is not satisfactory (Vrtiprah, 2006).

\footnotetext{
* University of Novi Sad, Faculty of Sciences, Department of Geography, Tourism and Hotel Management, Trg Dositeja Obradovića 3, 21000 Novi Sad, Serbia; Corresponding author: medics.ns@gmail.com
} 
Many elements of culture in Serbia, such as its material and spiritual culture, institutions, events, stand as a significant potential for the development of cultural tourism. However, cultural tourism in Serbia is still undeveloped because its cultural resources have not yet been transformed to the relevant products of cultural tourism. The cultural institutions are also not adequately included in tourist offer. Museums and galleries, as potentially the most attractive, still have traditional permanent exhibitions, poorly interpreted and mostly in Serbian. The interpretation is predominantly scientific and historical, and therefore unattractive to various target groups of visitors (Lazarević et al., 2OIO). Research has shown that visitors only read a small percentage of the wall panels and label copy in the museum on any given visit (Knudson, Cable \& Beck, 2003).

Managers of the world known museums agreed that museums in the future have to make a balance between managing collections and visitors. Involving visitors into dialogue and using museums' collections creatively are now the most important tasks for museums' employees. In the future only museums that really connect with their audiences will be sustainable. Therefore, visitors should be invited to actively participate. One of the ways to do such a thing is to accept and include new technologies in museums exhibitions. They could be an important part of interaction between visitors and museum management.

According to the Museums Associations' Mobile Survey from 2OI3, 50\% of surveyed museums in United Kingdom already have mobile experiences and $19 \%$ are planning to develop mobile experiences. Their main objective is "to provide an additional content to visitors" with 68\%, and almost as many (67\%) want "to provide a more engaging visitor experience."

There are several means for museums to communicate with their public through the digital technologies and this paper will focus on mobile technologies, especially on mobile applications and QR codes because they allow a high degree of personalization of the museum experience.

The aim of this research is the review of the concept of usage these technologies in museums which is now becoming an important part of revival of exhibitions and interaction with visitors and this is something what museums in Serbia missing. Methods which are used in research are: collection and analysis of existing relevant literature and documents.

\section{Usage of mobile technologies: QR codes and mobile applications}

Technology is becoming more and more popular in museums. Furthermore, museums around the world are now accessible on the web and through social media. Digital technologies have found their place in the modern museum in different forms. Mobile today could be pocketable or portable devices, smartphones or cellular phones, mobile or desktop websites, "bring your own device" mobile experiences or traditional on-site device distribution (Goldberg, 2OI3). The possibilities of usage of mobile technologies are various and numerous: QR codes, augmented reality, mobile phone wayfinding/GPS, applications, mobile websites, multimedia and audio tour, iPad tour etc. The next few chapters will focus only on QR codes and mobile applications as the very common in museums nowadays.

Quick Response Code or QR code is a type of two-dimensional barcode first designed in Japan in the Denso Wave, a Toyota subsidiary, in 1994 for the purposes of automotive industry. The QR code is similar to a bar code, but the difference is in the possibility of reading it with mobile phones and a bigger capacity for storing data (http://qrcode.meetheed.com). 
Due to its fast readability and various possibilities, the QR Code system has become more popular. In order to read a QR code it is necessary to have a QR code scanner. These scanners come built into various camera enabled mobile phones and third party scanner applications can be downloaded to almost any smartphone (iPhones, BlackBerries and Android phones). After taking a picture of a QR code, with the Internet access the application processes the code. It is recommended to have an open, password-free wireless network, as this provides the best experience for the most users. Once a QR code is scanned the decoded information can be used for various actions.

If the QR code is used for professional purposes, it's important to make sure that the code is tied in with QR code tracking and reporting capabilities so that company can monitor usage over time (http://hswsolutions.com).

The QR codes can be used in a number of ways, including advertising (in ad campaigns), marketing materials (all kind of printed materials, posters, brochures, business cards etc.) and clothes.

Fortunately, it is remarkably inexpensive to get started with QR codes and it is less expensive to maintain than other current technologies. A QR code is easily handled by designers and effortlessly integrated into the work flow of label production. The software for creating the codes is widely available on the Internet and mostly free (http://innogenesis.info). QR code is a hyperlink that connects the physical and the online world. QR codes can direct users to mobile landing pages that contain much more information and interactivity than can be afforded on the printed page.

A mobile application or a mobile app is a computer program designed to run on mobile devices such as a smartphone, tablet computer and other.

Apps are generally small, individual software units with limited function. This use of software has been popularized by App Store, which sells thousands of applications for the iPhone, iPad and iPod Touch. Each app provides limited and isolated functionality such as a game, calculator or mobile Web browsing. The simplest mobile apps take PC-based applications and port them to a mobile device (www.techopedia.com).

Mobile apps can come preloaded on the handheld device or can be downloaded by users from app stores or the Internet. We can say that there are three types of apps, native and web application and combination of these two, hybrid application:

I. Native apps are installed through an application store (Google Play or Apple's App Store) and are accessed through icons on the device home screen. They are developed specifically for one platform and cannot be deployed on another. These apps can take full advantage of all the device features (camera, GPS, list of contacts, etc). Also, native apps can use the device's notification system and can work offline. Native apps offer fast performance and access to native-device services but require additional resources to develop and maintain each platform, which can be expensive and time consuming.

2. Web apps are not real applications, they are really websites. They are run by a browser and typically written in HTML5. Users first access them as they would access any web page: they navigate to a special URL and then have the option of "installing" them on their home screen by creating a bookmark to that page. They require Internet connectivity.

3. Hybrid apps are part native apps, part web apps. Like native apps, they run on device and can take advantage of the many device features. Like web apps, they rely on HTML being rendered in a browser. Hybrid apps are also popular because they allow cross-platform development and thus significantly reduce development costs 
(the same components can be reused on different mobile operating systems) (www. nngroup.com).

\section{Usage of QR codes and mobile applications in museums}

The possibilities of mobile technologies usage are numerous and vary on effects that museum wants to achieve. In general, museums are exploring digital and mobile technologies to enhance the visitor experience and include visitors in communication.

In that way QR codes are limited only by the user's phone and the creator's imagination. Museums could direct the QR codes to extra information about an artist or piece of art. This information could be presented in different ways:

- Text: A great storage capacity gives opportunity to creators of each exhibition to write everything they want or believe that visitors would like to know.

- Games: In forms of quizzes or treasure hunts. In a treasure hunt each object of exhibition could be included with clues on reaching the next object. Prizes can be a product, service or free admission to another exhibition or event.

- Interaction with and between visitors: at the end of their visit, people could leave comments about their experience in the museum. This way, the museum would be able to have a closer look on their customers' opinions, which could improve the service provided. Visitors' feedback could be posted on museums websites where other visitors can respond to their comments, thereby creating some kind of forum for discussions

- Research: coded links to the web can prove useful in researching public opinions. Every time a museum visitor is directed to a page on the website, the museum can use special services to track the activity. In that way the museum can provide information which codes are used most frequently and which displays are the most popular.

- Website promotion: QR codes in printed materials can drive more traffic to a museum's website.

- Promotion of the gift shop: QR codes can be used to connect exhibitions' items with items in the museum gift shop. If an artefact is linked to the gift shop, visitors might be more likely to buy items related to their experience.

- Video: a code gives an opportunity to make pictures alive through reconstruction how the picture was made. It could be also linked with the You Tube video content.

- Choosing a path: using relevant cross-links, visitors can choose their own path through the museum instead of existing paths. In that way they can create their own unique learning experience.

- Augmented reality: hyperlinking, which is the ability to jump instantly from one concept to another, is the most powerful asset on the World Wide Web. The judicious use of QR codes can turn a museum or historic village visit into an experience in hyper-reality. A name augmented reality signifies the extension of real-world experience through additional sensory input such as sights, sounds and concepts which excite the imagination and expand perception (http://innogenesis.info).

Museums can use mobile application in various ways; also depending on the effect they want to achieve. According to authors Fisher \& Moses (20I3) they can be used for: 
- Location awareness - the app can determine the location of the visitor and tailor the experience to that location, and lets visitors to create custom tours.

- Gaming - app games are either single player or multiplayer, neither of which is designed to be social in real space. But the gaming model could be highly effective, because produces behaviors that are otherwise rare in conventional museum-going experience (collaboration and competition).

- Crowdsourcing - allows visitors or users the chance to contribute their own content to a museum exhibit (for example visitors can use their devices to record their own interpretations of objects within the exhibits).

- Polling - could be used to bring out users' responses to a variety of statements and questions. Polls could be designed to start conversation among visitors and encourage them to think critically about exhibit content. Providing latest poll results motivates visitors to vote and it places visitors within the larger social context of their community.

- Personalization and preferences - apps include features that allow the user to personalize their mobile museum experience in various ways. Gives user the ability to tick favorites, to customize their own tour of the exhibits, and to share their lists on Twitter and Facebook.

- Affinity mapping - affinity mapping utilizes a user's preferences or choices to identify affinities to virtually anything, including people, places and objects (such as "you might also like", related products and social matches). The comparison of like and dislikes could spur visitors to be more aware of their fellow visitors and how they fit into museum community.

Certainly there are some advantages and limitations of usage of these technologies in museums; they are listed in the table below.

Table 1. Advantages and limitations of the QR codes and mobile applications in museums

\begin{tabular}{|c|c|c|}
\hline & Advantages & Limitations \\
\hline $\begin{array}{l}\text { QR } \\
\text { codes }\end{array}$ & $\begin{array}{l}\text { Versatility: QR codes can be used for anything and } \\
\text { everything and could be beneficial for customers and } \\
\text { businesses. } \\
\text { Interaction: QR codes could be used to get feedback from } \\
\text { visitors or to connect them with each other through forum } \\
\text { or social media. } \\
\text { User-friendly: provides an easy process for directing users } \\
\text { to the website, phone number, directions, promotions or } \\
\text { other information. } \\
\text { Environmentally-friendly: QR Codes can make more } \\
\text { efficient use of printed materials and reduce waste. } \\
\text { Free: QR Codes cost nothing to produce. } \\
\text { Monitoring: actions triggered via QR Codes can be } \\
\text { tracked and reported so that company can monitor usage } \\
\text { of it. } \\
\text { Competitiveness: because QR Codes are still relatively } \\
\text { new, those who are among the first to employ them in } \\
\text { their outreach campaigns will set themselves apart as the } \\
\text { leaders in strategic marketing. } \\
\text { Survey: sometimes is very hard to get customers to com- } \\
\text { plete surveys. QR codes give customers the opportunity } \\
\text { to participate at any time they want. }\end{array}$ & $\begin{array}{l}\text { Lack of familiarity: there is still a large demographic in } \\
\text { society that still don't know what QR codes represent and } \\
\text { how they are used. Therefore, it is advisable to set some } \\
\text { panels or leaflets with short how-to-guides. } \\
\text { Aesthetic: people find them ugly. } \\
\text { Resistance: QR codes are favorite mainly to the young } \\
\text { people who are a great user of the internet and new tech- } \\
\text { nologies. There could be a certain resistance towards QR } \\
\text { codes and such types of promotion. } \\
\text { Dependability: the whole concept of a QR code is strictly } \\
\text { based on its ability to be scanned by a mobile device. So, } \\
\text { the visitor needs a device and good internet connection. } \\
\text { Illegible: because QR codes appear on printed material, } \\
\text { there is always an issue that print quality can cause the } \\
\text { code to be unreadable. The best way to avoid this is to test } \\
\text { them before distribution. } \\
\text { Bad optimization of internet sites or bad navigation: for } \\
\text { the customer, the mobile experience with the QR code } \\
\text { could be disappointing, when codes lead to non-mobile } \\
\text { optimized sites or dead links. }\end{array}$ \\
\hline
\end{tabular}




\begin{tabular}{|c|c|c|}
\hline & Advantages & Limitations \\
\hline $\begin{array}{l}\text { Mobile } \\
\text { Apps }\end{array}$ & $\begin{array}{l}\text { Versatility: mobile app can be used for anything and } \\
\text { everything (games, business productivity applications, } \\
\text { media applications, time management, etc.). It could be } \\
\text { beneficial for customers and businesses. } \\
\text { Interaction: mobile app could be used to get feedback } \\
\text { from visitors or to connect them with each other through } \\
\text { social media. } \\
\text { Individuality \& personalization: visitors can create their } \\
\text { own highlights, with the ability to search, group, and filter } \\
\text { every object. } \\
\text { Analytics: it is possible to add tracking to discover the } \\
\text { actions of the user. } \\
\text { Comparison: the mobile platform can give the visitor the } \\
\text { ability to compare and contrast objects and in that way } \\
\text { provide a valuable content. } \\
\text { User-generated content: collected content, in the form } \\
\text { of comments, thoughts or responses could give the muse- } \\
\text { um valuable research tool. Also when a visitor is viewing } \\
\text { an object, the device has possibility to suggest additional } \\
\text { (related) objects. } \\
\text { Voting: when a visitor choose a specific tour or object, it is } \\
\text { possible to publish that to the mobile platform for use by } \\
\text { other visitors. Lists of these could be voted upon by users, } \\
\text { giving them the ability to select from "most travelled" or } \\
\text { "most highly rated" tours etc. }\end{array}$ & $\begin{array}{l}\text { Dependability: the whole concept is strictly based on } \\
\text { mobile device. Apps are limited to phone platforms, and } \\
\text { some of them depend on internet connectivity. } \\
\text { Availability: requires customers to download it before } \\
\text { they can experience it. They are not instantly available } \\
\text { Costs (developing, maintaining, and marketing): require } \\
\text { the long term investment, updates to an app every few } \\
\text { months. But it can generate revenue if one establishes a } \\
\text { price for a user to download app. } \\
\text { Short lifecycle: the lifecycle of most mobile apps is very } \\
\text { short before an entirely new app must be created. } \\
\text { Anti-social \& virtual: no matter how socially engaged } \\
\text { someone who is tweeting about their museum experience } \\
\text { might be, for that moment in time, they are just another } \\
\text { museum-goers looking at their mobile device, distracted } \\
\text { from the world around them. } \\
\text { Bad optimization of internet sites or bad navigation: for } \\
\text { the customer, the mobile experience could be disappoint- } \\
\text { ing, because it could lead to non-mobile optimized sites or } \\
\text { even dead links. }\end{array}$ \\
\hline
\end{tabular}

Museums have to understand audience needs before starting to use digital technologies. It is important to know what the effects of using certain types of technologies are and what reactions of museum visitors they can cause. For both above mentioned mobile technologies, the common advice is to keep it simple. Too much text, actions needed or too many possibilities could confuse the user and discourage him/her to continue to use it.

It is important to give visitors the opportunity to engage with other visitors, the museum community or employees (the opportunity to give comments on different topics, connecting with other visitors through insight of others' thoughts or beliefs, or give curators the opportunity to directly speak to visitors and answer their questions). In that way museums will bring more engagement to visitors on one hand and on the other it will have some insights on their thoughts and perceptions, which could be an important research tool.

The one of the most significant things in mobile technologies usage is the content. Firstly, it is important to give the visitors details that aren't visible in the museum setting. The best way to do that is to answer these questions (Goldberg, 20I3): How would it have been originally experienced or used? How heavy the object is? What does it feel like? What are the users memories associated with imagery in a work, historical objects, or displays (for example via links to social media). Also the virtual reality could be used to bring an object's original location or setting into the present time.

\section{Discussion and Conclusion}

Digital technologies have affected every aspect of our lives, also every industry, company and organization including museums and galleries. Museums now have the ability to engage the visitor in new ways and have the opportunity to create a memorable, unique experience. Digital technologies can deliver large volumes and personalized information to target dif- 
ferent learning styles and requirements, and this is what makes the technology so versatile and may lead to exciting new possibilities for museums in the future (Tallon, Walker, 2008). Using the new technologies could lead to interpretation of a cultural content in a new manner and change the way of presenting the cultural heritage. That should impact interests for cultural events and contents in the cultural institutions (museums, galleries). In the countries such as Serbia, where cultural habits are on a very low level, new technologies can help in arousing the participation in culture, especially among the young population. They use the internet as a main source of information, fun and education. According to the latest research about the cultural life of students even $85.8 \%$ of high school students (Mrđa, 2OIIa) and almost as many university students, $83.5 \%$, in Serbia rarely or never pay a visit to museums. Some of the causes of such results are: the low standard of living, lack of free time, weak interest and the unsuitable offer (Mrđa, 2OIIb). Also we could mention that $86,4 \%$ of high school students (Mrđa, 20IIa) and 76,5\% of university students (Mrda, 2OIIb) have profile on some of the social networks. It should be mentioned that interest in the additional audio-visual and interactive content increases and culminates at age from I9 to 26 (Gavrilović, 2OII).

Interactive exhibitions remain a largely untapped laboratory for systematic research to investigate how people learn in an informal environment (Stevenson, I99I). What is clear, though, from the few studies that have been conducted, is that visitors enjoy using interactive exhibits and that electronic media and digital technologies have been secured a home in the twenty-first century museum (Hilke, I988). Nowadays QR codes become obvious in all kinds of printed materials, on products and in public places. It is essential to raise public awareness about the possibilities of QR codes, in order for them to become one of the elements of the brand making in the future. These codes give museums the opportunity to engage the public in new ways and give various experiences. In that manner, the present stereotypes, for example, the static of museum exhibitions and cultural heritage, its monotony, non-creativity and a traditional way of presenting, collapse with usage of digital, multimedia technologies which can be used primarily in creating a new experience and reliving of the cultural heritage (Rikalo, Mikić, 2OI2). On the other hand, mobile applications are very popular at the moment. According to Portio research I.2 billion people worldwide were using mobile apps at the end of 2OI2. This is forecast to grow at a 29.8 percent each year, to reach 4.4 billion users by the end of 2OI7; around $20 \%$ of users are from Europe (http://mobithinking.com). But we have mentioned that they are expensive to be maintained and be up-to-date and finally be constantly interesting for visitors. Costs can be overcome with different sponsors and donors (with their logos on interactive kiosks and published guides, etc.).

In the future, museums will need audience research and more understanding how to improve device adoption rates among their visitors.

The best way for any museum to decide whether to try mobile technologies or not is to ask the following questions. How popular is this technology now and how is going to be? Who are the people who use them? What age are they? Why should or should not use this technology to bring different experience into the museum?

There are some debates about using these technologies in museums, but overall they can be used in different ways and have different impacts. Owing to that they have to be observed as only one way of presentation, and definitely not as the only one. They certainly are an excellent way to enhance the visitor's experience. They can bring life to exhibits, allow communication between visitors and educate at all levels. 


\section{References}

Fisher, M., Moses, J. (2OI3). Rousing the Mobile Herd: Apps that Encourage Real Space Engagement. Museums and the Web 2OI3, The annual conference of Museums and the Web, Portland, OR, USA.

Gavrilović, E. (2OII). Museum public in Serbia. Center for study in Cultural Development. Belgrade, $70-77$.

Goldberg, S. (2OI3). Content for all kinds: Creating content that works for on- and offsite visitors. Available at: http://mobileappsformuseums.wordpress.com

Hilke, D.D. (1988). The Impact of Interactive Computer Software on Visitor's Experiences: A Case Study, ILVS Review, I(I), 34-49.

Knudson, D., Cable, T. \& Beck, L. (2003). Interpretation of Cultural and Natural Resources. State College, PA: Venture Publishing Inc, 2II.

Lazarević A. et al. (2OIO). Cultural policies in cities of Serbia. Center for study in Cultural Development. Belgrade.

Mrda, S. (2OIIa). Cultural Life and Needs of High School Students in Serbia. Center for study in Cultural Development. Belgrade.

Mrđa, S. (2OIIb). Cultural Life and Needs of Students in Serbia. Center for study in Cultural Development. Belgrade.

Rikalo M., Mikić, H. (2OI2). QR Codes in Creative Economy: Case Study on Vinca Archaeological Site. Applied Internet and Information Technologies, 294-298.

Smith, K. (2009). The Future of Mobile Interpretation. Museums and the Web 2009. The annual conference of Museums and the Web. Toronto. Canada.

Stevenson, J. (I99I). The Long-term Impact of Interactive Exhibits, International Journal of Science Education, I3(5), 52I-53I.

Tallon L., Walker K. (2008). Digital Technologies and the Museum Experience: Handheld Guides and Other Media. Alta Mira.

Tallon, L. (2OI3). Mobile Strategy in 2OI3: an analysis of the annual Museums \& Mobile survey. Available at: www.museums-mobile.org/survey

Vrtiprah V. (2006). Cultural Resources as a Tourist Supply Factor in the 2Ist Century. Ekonomska misao i praksa I5(2), 279-296.

World Tourism Organization (2OOI). Tourism 2020 Vision: Volume 7: Global Forecasts and Profiles of Market Segments. World Tourism Organization (UNWTO).

Dave Barr2 $(2 \mathrm{OI} 2,07,06)$. QR Codes in The Museum Context: Part I [The text of this post first appeared in article, "Museums Bring QR Codes Into Play", published in MUSE, vol. XXX, 4, 34-37, July 2OI2.] Retrieved from http://innogenesis.info/2OI2/O7/qr-codesin-the-museum-context-part-I

\section{$\propto$}

http://enoxmedia.com/Blog/Mobile-Website-Vs.-Mobile-App-Advantages-And-Disadvantages-Of-Each

http://mobileappsformuseums.wordpress.com

http://mobithinking.com/mobile-marketing-tools/latest-mobile-stats/e\#appusers

http://qrcode.meetheed.com/technical.html

http://smithsonian-webstrategy.wikispaces.com/Mobile

http://uqr.me/2OI3/O2/qr-codes-in-museums/ 
www.estateqrcodes.com/advantages-disadvantages.html www.hswsolutions.com/services/mobile-web-development

www.lemproject.eu

www.museum-id.com/idea-detail.asp? $i d=283$

www.nngroup.com/articles/mobile-native-apps

www.pro.rcip-chin.gc.ca/media/pro/carrefour-du-savoir-knowledge-exchange/ansm_ qr/codes_qr-qr_codes-eng.pdf

www.techopedia.com/definition/2953/mobile-application-mobile-app 